\title{
An overview of systematic reviews on the collaboration between physicians and nurses and the impact on patient outcomes: what can we learn in primary care?
}

Evi Matthys ${ }^{*}$ (i), Roy Remmen and Peter Van Bogaert

\begin{abstract}
Background: Primary care needs to be strengthened in order to address the many societal challenges. Group practices in primary care foster collaboration with other health care providers, which encourages care co-ordination and leads to a higher quality of primary care. Nursing roles and responsibilities expanded over time and nurses have been found to often provide equal high-quality chronic patient care compared to physicians, even with higher patient satisfaction. Inter-professional collaboration between primary care physicians and nurses is a possible strategy to achieve the desired quality outcomes in a strengthened primary care system. The objective of this research is to synthesize the evidence presented in literature on the impact of collaboration between physicians and nurses on patient outcomes in primary care or in comparable care settings.

Methods: A systematic review of peer-reviewed reviews was performed in four databases: COCHRANE, MEDLINE, EMBASE and CINAHL. All studies from 1970 until May 222016 were included in the search strategy. Titles, abstracts and full texts were respectively reviewed. At least two of the three authors independently reviewed each of the 277 abstracts and 58 full texts retrieved in the searches to identify those which contained all the inclusion criteria. Two authors independently appraised the methodological quality of the reviews, using the AMSTAR quality appraisal tool.

Results: A total of eleven systematic reviews met all the inclusion criteria and almost fifty different patient outcomes were described. In most reviews, it was concluded that nurses do have added value. Blood pressure, patient satisfaction and hospitalization are patient outcomes where three or more systematic reviews concluded better results when physicians and nurses collaborated, compared to usual care. Colorectal screening, hospital length of stay and healthrelated quality of life are outcomes where collaboration appeared not to be effective.
\end{abstract}

Conclusions: Collaboration between physicians and nurses may have a positive impact on a number of patient outcomes and on a variety of pathologies. To address future challenges of primary care, there is a need for more integrated inter-professional collaboration care models with sufficiently educated nurses.

Keywords: Nurse, Physician, Primary care, Collaboration, Inter-professional, Patient outcome, Education

* Correspondence: Evi.Matthys@uantwerp.be

University of Antwerp, Campus Drie Eiken DR334, Universiteitsplein 1, 2610

Wilrijk, Belgium 


\section{Background}

Populations around the world are rapidly ageing. It is estimated that between 2015 and 2050, the world's population of over 60 year olds' will nearly double from 12 to $22 \%$ [1]. As people age, they are more likely to experience several health conditions at the same time. The demand for health care is evolving rapidly in the context of an ageing population and the growing number of people living with one or more chronic conditions [2]. In Europe, patients are more demanding and expect health care to be accessible and high qualitative at the same time [2, 3]. Professional caregivers, on the other hand, experience a high workload and demand a better work-life balance $[4,5]$. At the same time, financial resources in health care are decreasing, while the demand for financial support is increasing [6-8]. In an attempt to address these challenges, the following four aims have the potential to guide innovations in health care delivery: improving the health of populations, improving the experience of care, reducing per capita costs of health care, and diminishing the workload for professional caregivers so they can rediscover meaning and joy in their work $[7,9,10]$.

Reforms are shifting care from hospitals to community, partly due to a growing prevalence of chronic diseases [11, 12]. In addition, countries in the European Union show many potentially avoidable hospital admissions for several chronic conditions including diabetes mellitus, chronic heart failure, chronic obstructive pulmonary disease and asthma. Potentially avoidable hospitalizations for these conditions are commonly used to measure access and quality of primary care systems $[13,14]$. In order to address the needs of ageing populations and to reduce the unnecessary use of hospital care, primary care systems should be strengthened [2].

It was suggested that group practices in primary care foster collaboration with other health care providers, which encourages care co-ordination and leads to a higher quality of primary care [8]. Primarily, nurses were introduced in primary care practices to meet a perceived shortage of primary care physicians [15]. Over time, nursing roles and responsibilities expanded. Practice nurses were able to provide holistic care for patients that was not limited to traditional nursing boundaries [16]. Nurses have been found to often provide cost effective patient care and equal high-quality chronic patient care compared to primary care physicians, even with higher patient satisfaction $[2,12,16,17]$. By expanding the roles and responsibilities of nurses, primary care systems can be strengthened.

Improved inter-professional collaboration is important and diversity of disciplines is needed in a time when the provision of primary health care becomes more complex and one health professional can no longer meet all patient needs $[18,19]$. As the largest health care workforce group, and because of their specific skills and competencies, nurses are in an ideal position to collaborate with other team members in the delivery of more accessible and effective chronic disease management in primary care. Inter-professional collaboration between primary care physicians and nurses is a possible strategy to achieve the desired quality outcomes in an effective and efficient manner in an integrated health system. Therefore, there's a need to explore to what extent an integration of physician and nurse competencies impacts patient outcome.

The objective of this research is to synthesize the evidence presented in literature on the impact of collaboration between physicians and nurses on patient outcomes in primary care or in comparable care settings.

\section{Methods}

\section{Data sources}

We searched for reviews of the literature containing synthesized evidence relating to collaboration between physicians and nurses, and the impact of their collaboration on patient outcomes.

Searches were performed in four literature databases: COCHRANE, MEDLINE, EMBASE and CINAHL. All databases were searched from 1970 (or from their inception if this was later than 1970) until May 2016. In addition, reference lists of the selected reviews were reviewed to identify other eligible reviews, but no additional review articles were identified.

All detailed search strategies can be found in Additional file 1.

The retrieved references were entered into Endnote ( and duplicates were removed.

\section{Study selection}

The included studies had to fulfil a number of criteria in order to be included. First, the manuscript had to be a systematic review of the literature. A review was considered a systematic review if two of the following criteria were met: a search strategy was reported, a search was performed in Medline(PubMed) at least, and the included studies were subjected to a methodological assessment. There were no inclusion criteria based upon the research design of the primary research articles included in the systematic reviews.

Second, the manuscript needed to concern 'collaboration between physicians and nurses' in a primary care setting or in a hospital setting. Since there is no generally accepted definition of what inter-professional collaboration means, the intervention was defined as collaboration by the researchers if at least one physician provided care along with at least one nurse. 
Third, the outcomes in the reviews needed to concern clinical patient outcomes and/or patient satisfaction outcomes. The review also needed sufficient methodological quality according to the AMSTAR quality appraisal tool (studies with a score $\geq 11$ were included) [15-17]. And finally, none of the exclusion criteria listed below were met.

Research publications were excluded when they were primary research studies, when they were written in a language other than English or Dutch, or when the setting was considered 'inappropriate'. Settings were defined as inappropriate when the presented patient population was dissimilar or incomparable to the primary care population. Inappropriate settings were determined as; an intensive care unit (ICU), radiology, neonatology intensive care unit (NICU), obstetrics and gynecology. Studies were also excluded when the outcomes merely concerned nurse/physician outcomes.

A four-stage inclusion process was applied. Initially, titles and abstracts of research articles identified from the search strategies were screened, in order to determine their relevance and whether they met the inclusion criteria. No further analysis was done on the subsequent criteria as soon as one criterion was not met. In the first stage, one reviewer screened all references. When the title provided insufficient information to determine inclusion or exclusion, the research article proceeded to the second stage.

In the second stage, two reviewers independently examined all abstracts of the articles selected in the first stage, in order to determine whether they met the inclusion criteria. Any disagreements were resolved by discussion between the two reviewers.

In the third stage, two reviewers independently examined all full texts of the articles selected in the second stage. Any disagreements were resolved by discussion between the two reviewers. If no agreement could be reached, a third reviewer decided.

The final stage of inclusion related to the methodological assessment of the reviews. All reviews remaining after the third stage, were assessed with the AMSTAR quality appraisal tool $[15,17]$. This assessment tool was formed by combining the enhanced Overview Quality Assessment Questionnaire (OQAQ), a checklist created by Sacks, and three additional items judged to be of methodological importance. 11 different components were identified [15]. The eleven criteria were scored as followed: 2 points were given when the criterion was fully met, 1 point when it was partly met and zero points when it was not met. Therefore, a maximum of 22 points on methodological quality could be achieved (see Table 2). Two reviewers independently examined the methodological quality of the reviews, using the AMSTAR quality appraisal tool [18]. The mean of the scores of the two reviewers was computed and classified as the final quality score [17]. In case the scores of the reviewers differed more than two points, reviewers reached consensus by discussion. Only moderate and high quality reviews (mean scores $\geq 11$ ) were used for data extraction.

\section{Data-analysis and synthesis}

Data were extracted about the search strategies, time frame of the searches, studied interventions, selected outcomes, selected patient populations, selected study setting, the collaboration between physician(s) and nurse(s) and the different nursing roles within the collaboration.

Data-analysis was done primarily by description of the characteristics, interventions and outcomes. Metaanalyses and quantitative assessments from the included reviews were described. No quantitative pooling was performed across the reviews.

\section{Results}

Search and inclusion results

After duplicates were removed, the searches in the different databases resulted in one unique database, encompassing 4004 studies. Titles, abstracts and full texts were respectively reviewed and subsequently 277 studies and 58 studies were identified as potentially meeting the inclusion criteria (See Fig. 1). A total of 36 systematic reviews met all the inclusion criteria. Two reviewers independently assessed the remaining 36 reviews on their methodological quality, using the AMSTAR quality appraisal tool. A mean of the two scores was computed and classified as the final quality judgement. Eleven systematic reviews had a mean quality score higher than 11 and were included for data-extraction and analysis.

The flow diagram of the inclusion process is shown in Fig. 1.

Characteristics of the 11 included systematic reviews.

Search periods for each systematic review are shown in Table 1.

A narrative overview of the included review articles is described in Table 2 . The eleven reviews only included quantitative studies. Four reviews [19-22] were limited to randomized controlled trials only, while the other seven reviews also included other comparative designs such as controlled before and after studies, interrupted time series and intervention studies. Three reviews included observational studies [23-25]. One review author additionally included other systematic reviews [26].

Four systematic reviews performed a meta-analysis [21, 26-28]. The methodological quality of the included review articles varies from moderate [20, 24] to high $[21,28,29]$. Nine review articles included 


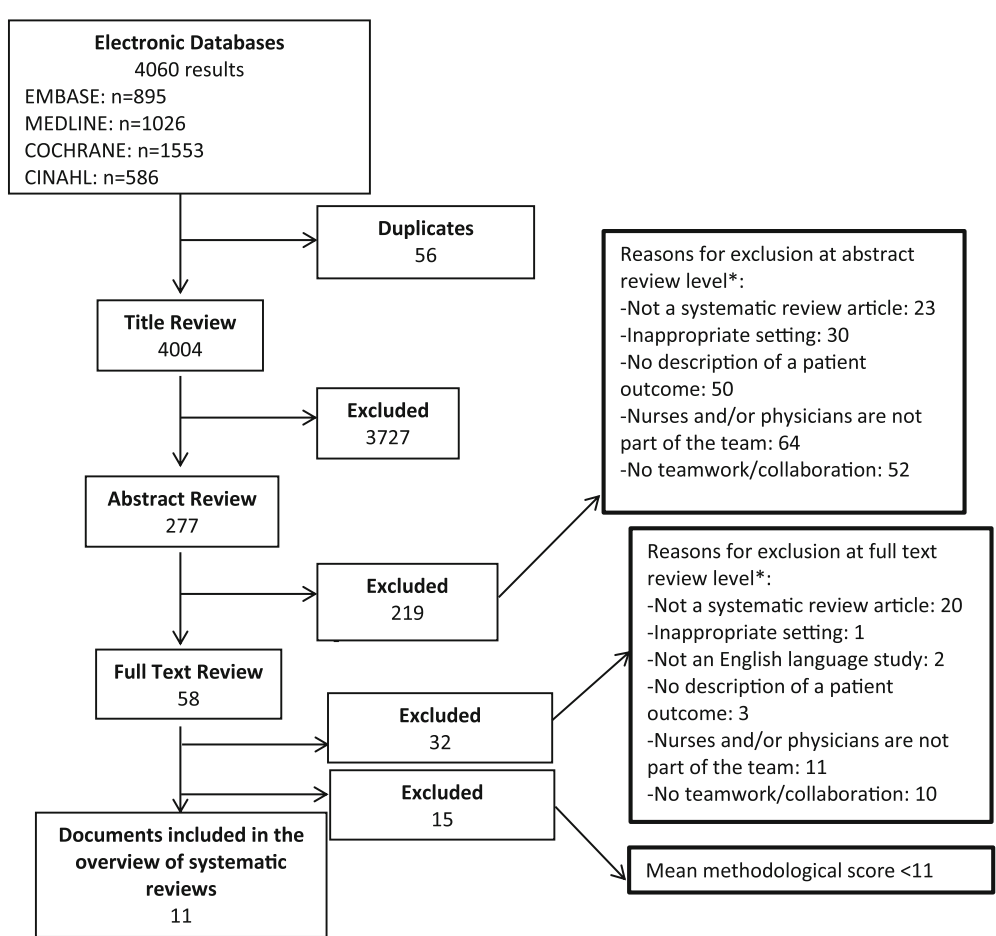

Fig. 1 Search strategy. Presents the search strategy of this overview of systematic reviews. The reasons for exclusion after reviewing the abstracts and full texts are presented on the right. *Reasons for study exclusion can be attributable to more than one category

studies that were conducted in both a primary care setting and a hospital setting [19-24, 26, 28, 29]. Two review articles included studies that were exclusively conducted in a hospital setting [25, 27].

The eleven systematic reviews included a total of 285 different primary studies, the number of primary studies included in the review articles varies from 6 to 69. Most of the primary studies were included only once in a review, with the exception of 12 papers that were included

Table 1 Search periods in included review articles

\begin{tabular}{ll}
\hline Review article & Search period \\
\hline Allen et al. 2014 & $1990-2013$ \\
Aubin et al. 2012 & $1947-2009$ \\
Health Quality Ontario. 2013 & Inception-2012 \\
Health Quality Ontario. 2014 & 2000-2013 \\
Martin et al. 2010 & $1999-2009$ \\
Newhouse et al. 2011 & $1990-2008$ \\
Renders et al. 2000 & $1966-1999$ \\
Shaw et al. 2014 & $1980-2014$ \\
Smith et al. 2014 & $1990-2011$ \\
Snaterse et al. 2016 & $1990-2015$ \\
Stalpers et al. 2015 & 2004-2012 \\
\hline
\end{tabular}

in two reviews. Additional file 2 presents a list of all primary studies included in at least one of the reviews.

Table 3 presents the main findings of the metaanalyses. Four different review articles are presented. The table includes: intervention, control group and the different outcomes. The number of studies within the systematic review and the total number of patients are presented, followed by the (weighted median) effect size, a measure of heterogeneity and an appraisal of the quality of evidence/risk of bias (if available). The included systematic reviews provided no information on the performance of a statistical process for small-study effects. The table shows that interdisciplinary teams targeting either informational or management continuity had a positive impact, with a weighted median effect size (95\% confidence interval) of respectively $2.0 \%(-0.03,3.20)$ and $2.0 \%(-1.90,3.20)$, on the quality of life of patients diagnosed with cancer. A measure of heterogeneity was not available. The quality of evidence of the included research articles, according to GRADE, was rated very low. Team based models of end-of-life care (home and comprehensive) caused a decrease in the number of people admitted to hospital and an increase of the number of people dying at home. Nurse-coordinated care as well as nurse-managed protocols had a positive effect on patients' blood pressure and caused a decrease in patients' low-density lipoprotein cholesterol levels. 


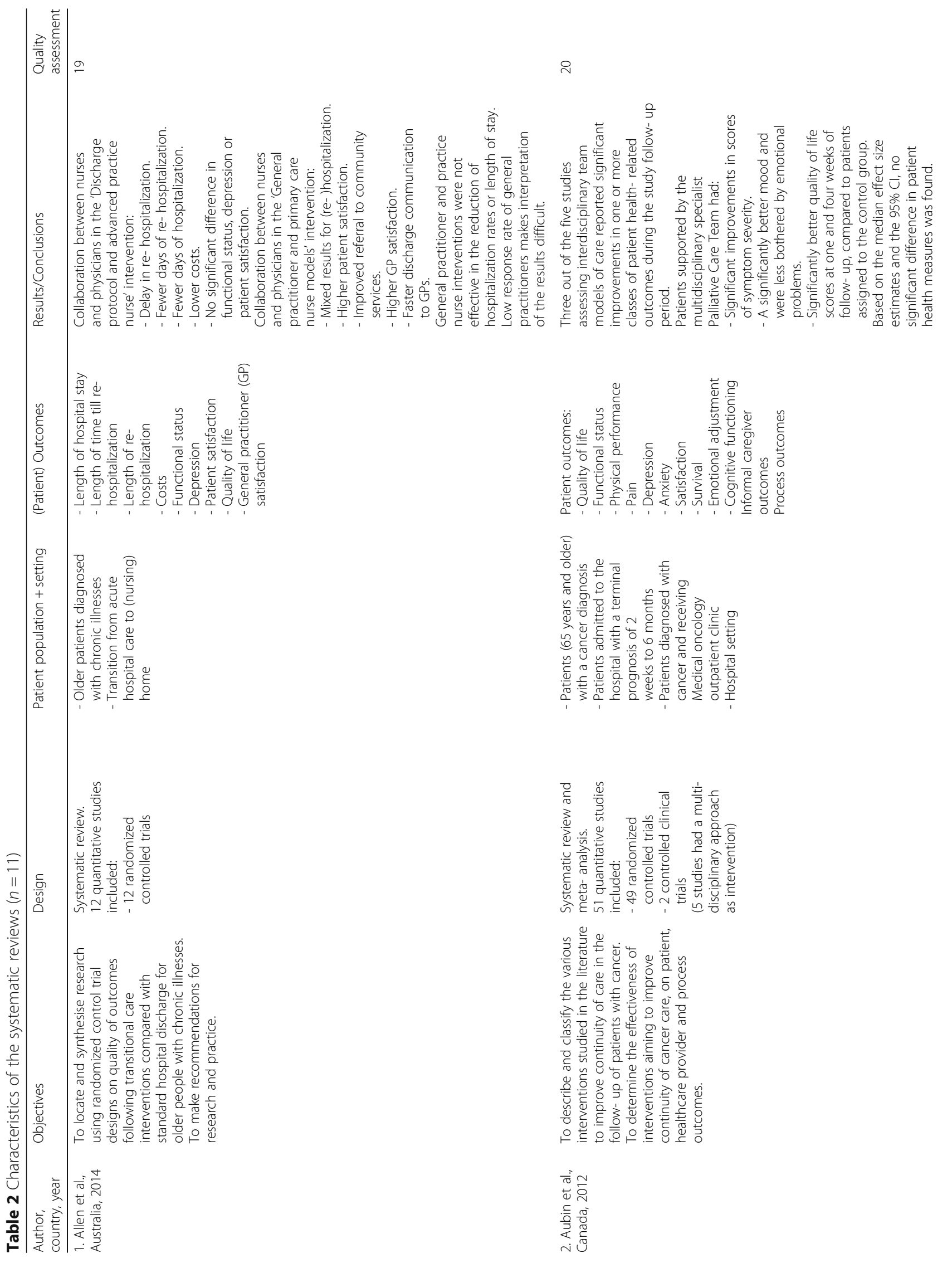




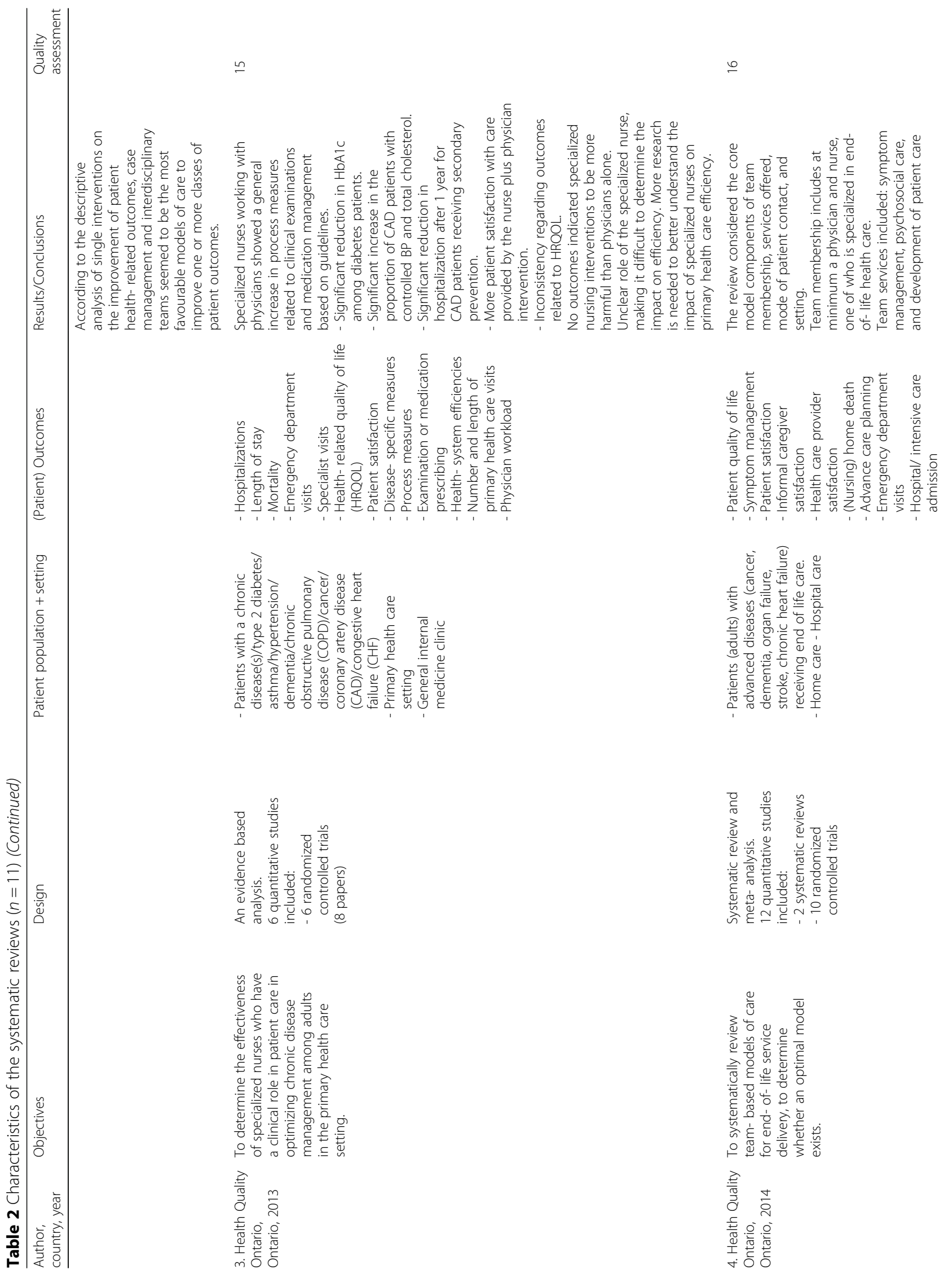




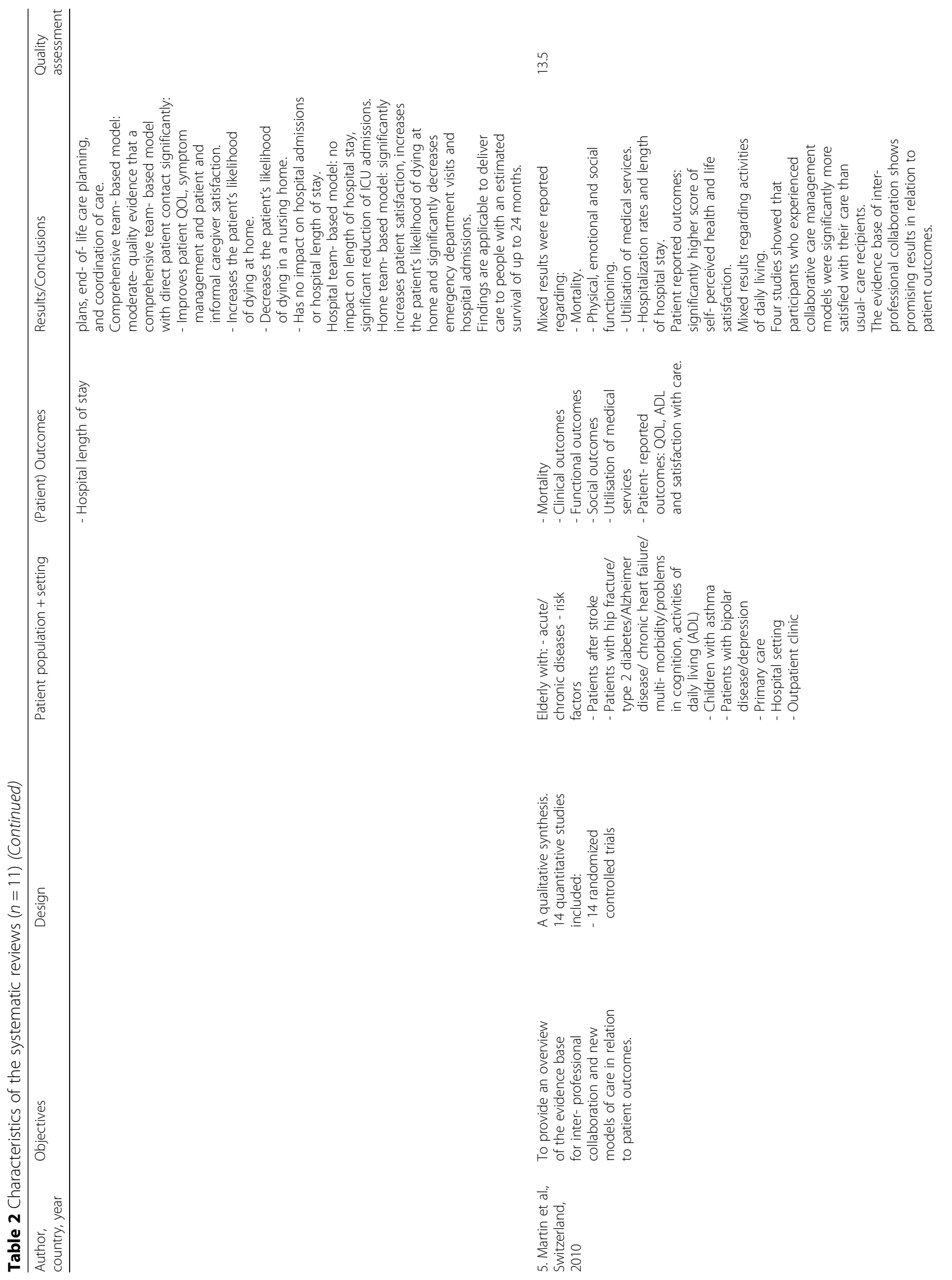




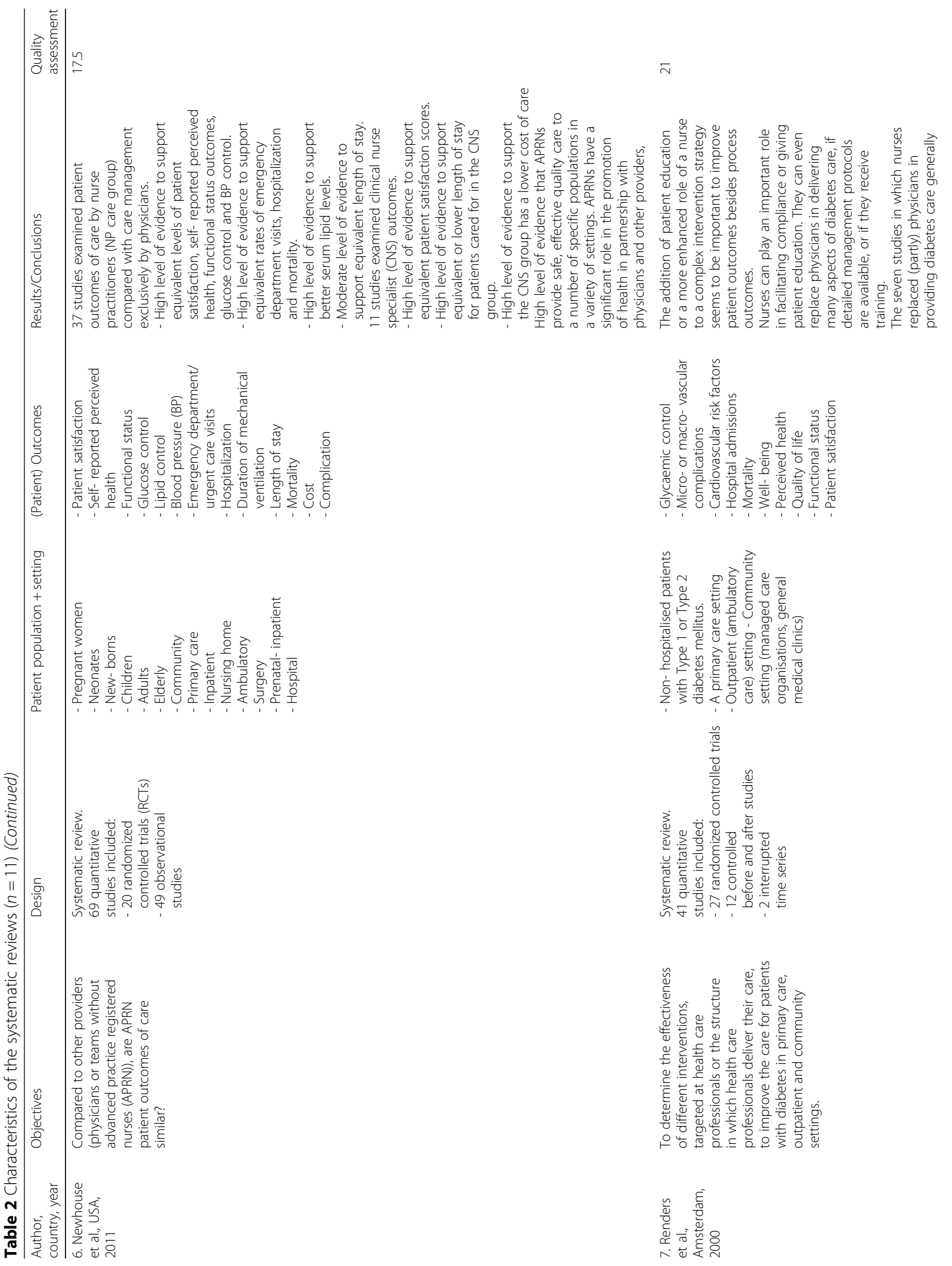




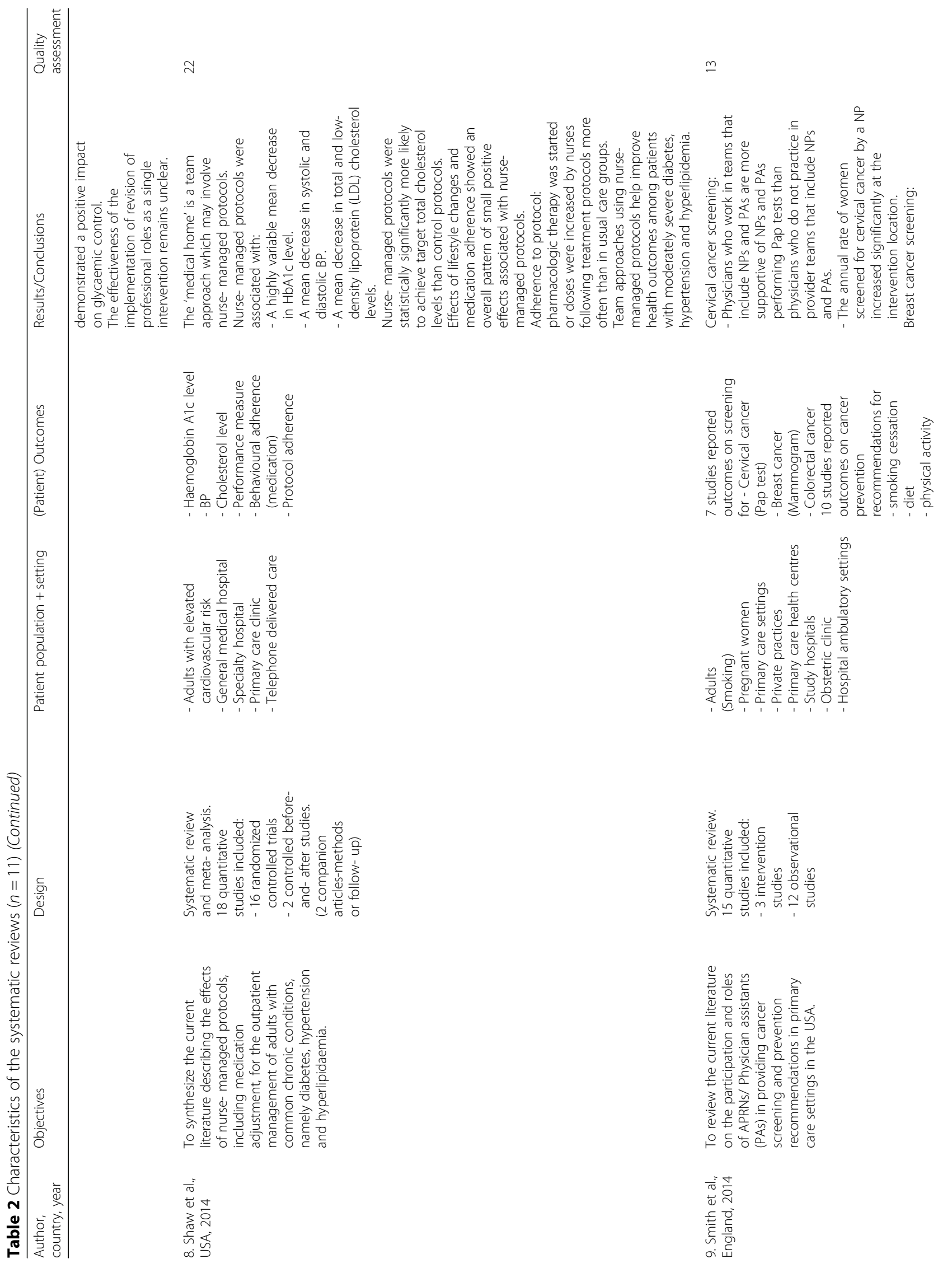




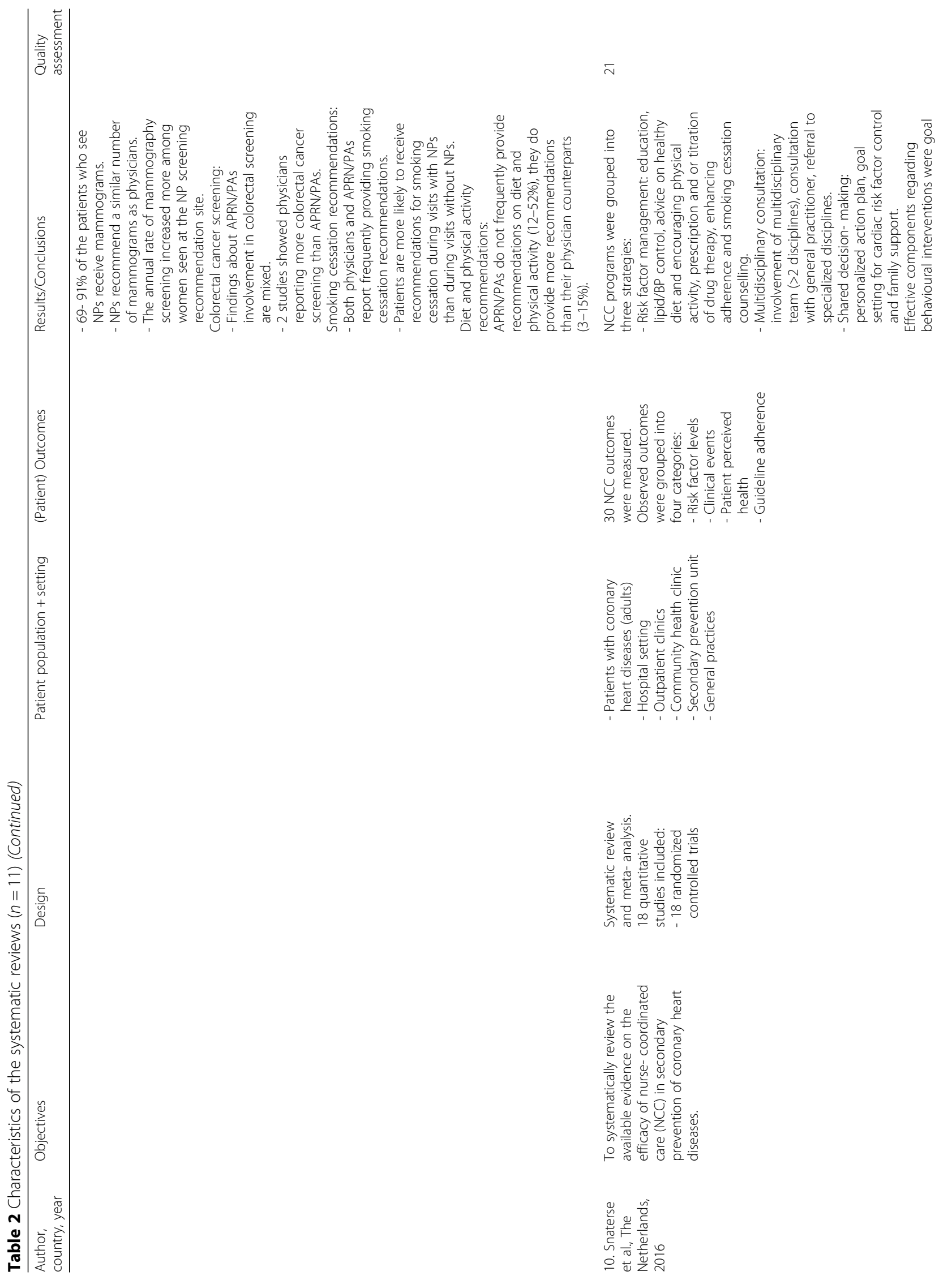




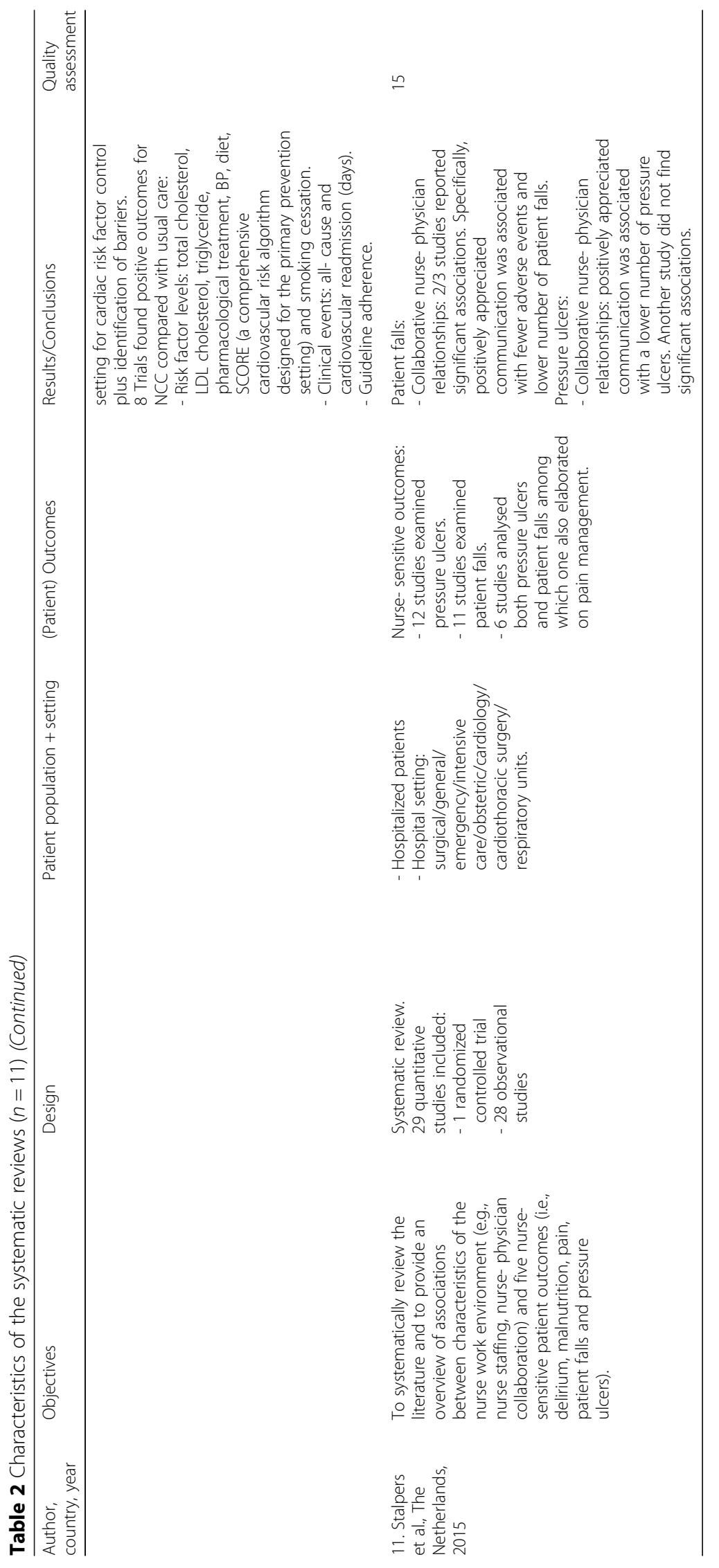




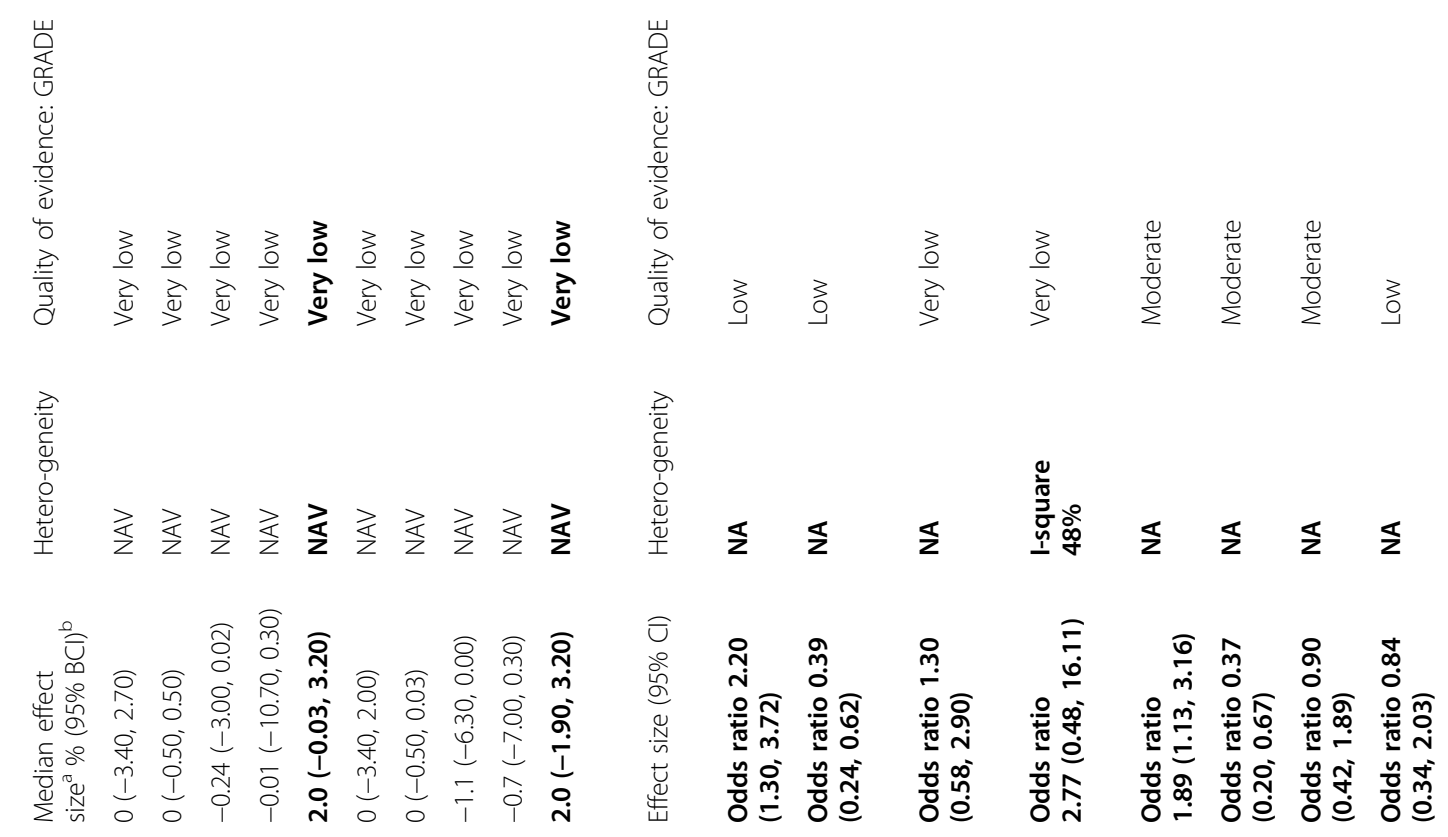

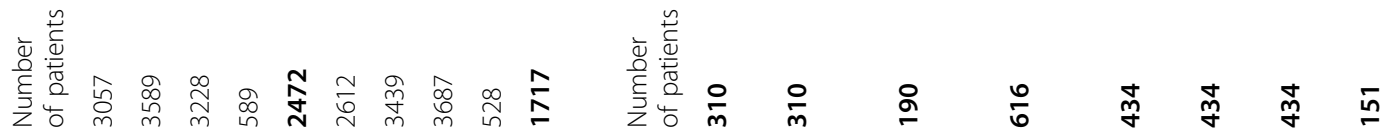

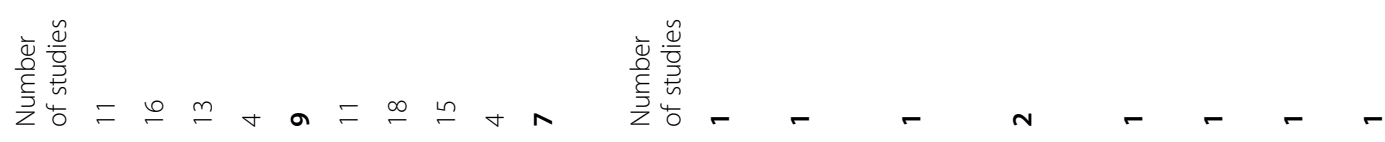
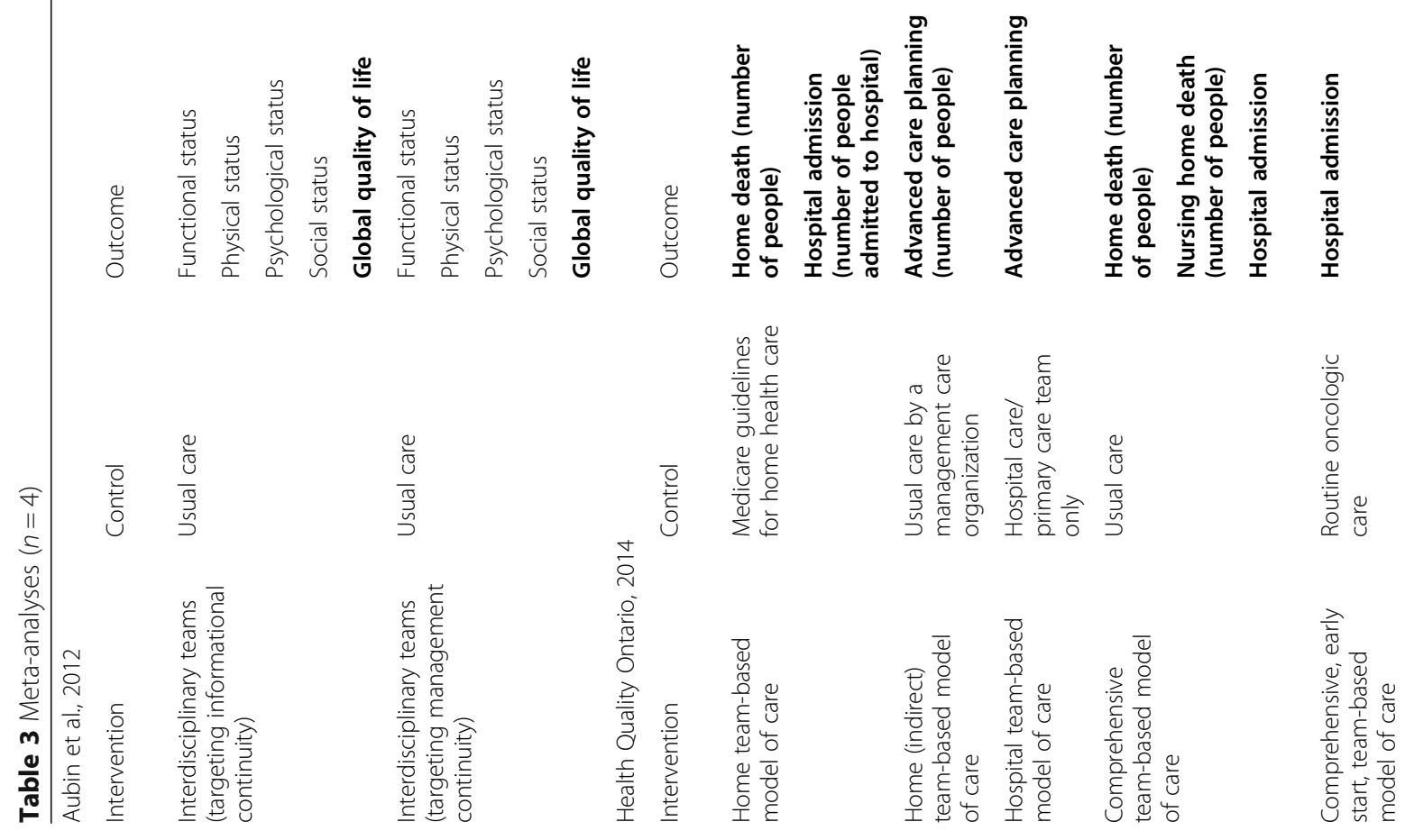

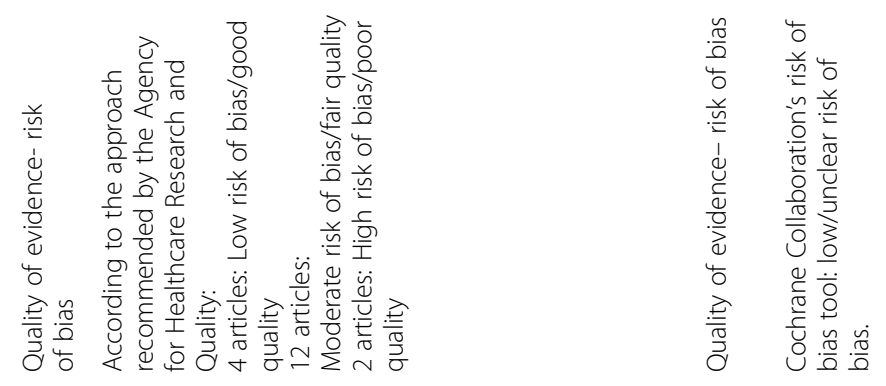

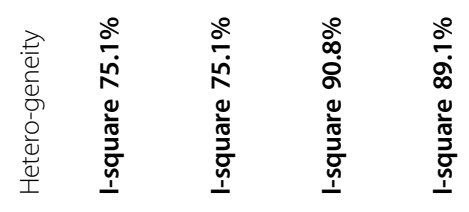

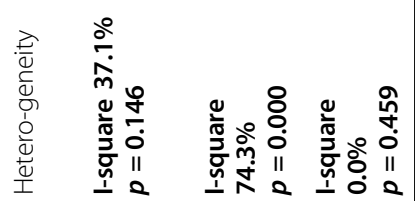

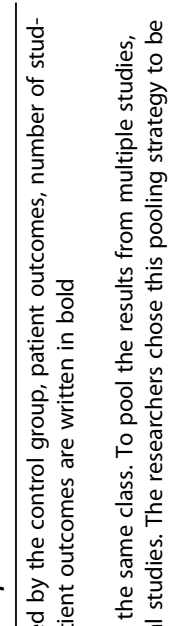

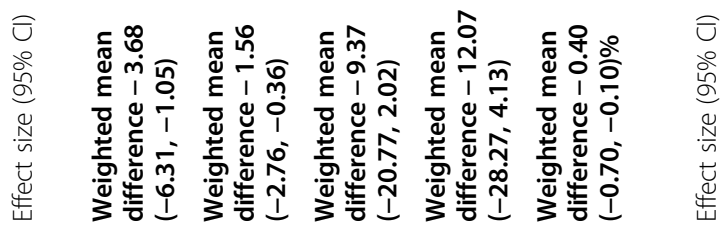
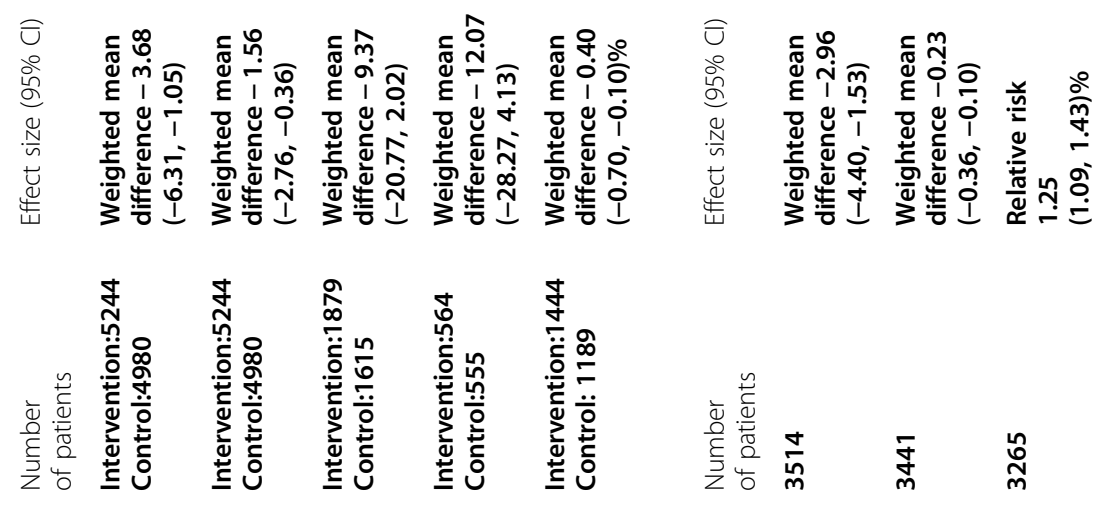

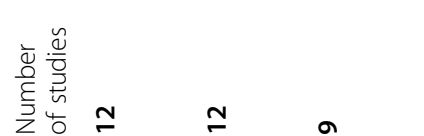

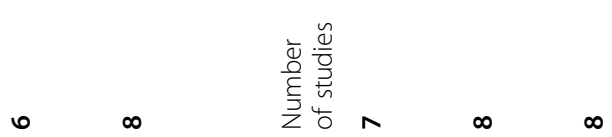

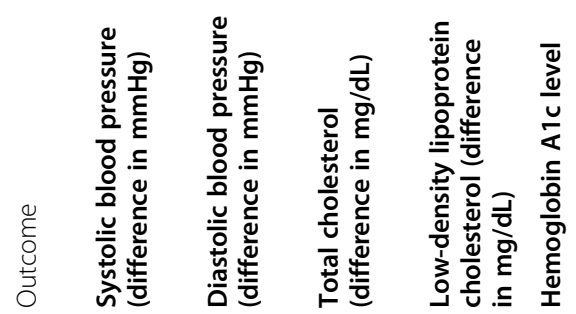

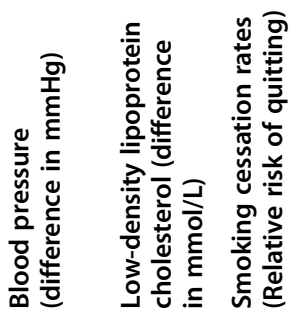

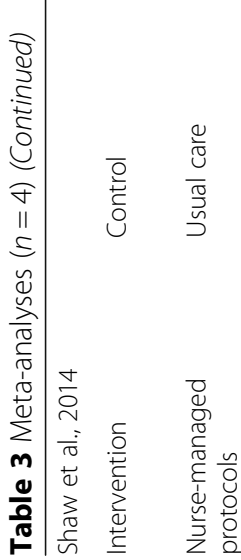

离离离

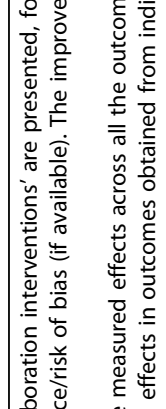

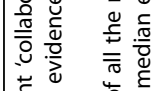

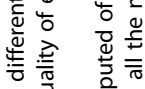

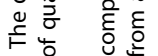

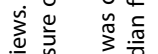

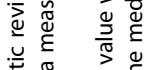

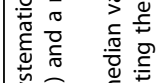

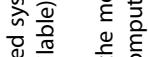

要

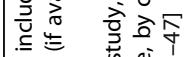

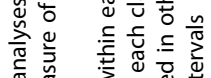

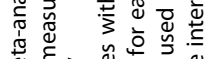


Table 4 presents an overview of the systematic reviews that did not provide a meta-analysis. Seven different review articles are presented. The table includes: intervention, control group and the different outcomes. The number of studies within the systematic review and the total number of patients are presented, followed by a statement on heterogeneity (if available) and an appraisal of the quality of evidence/risk of bias (if available).

All eleven articles describe the impact of collaboration between physicians and nurses on patient outcomes. Table 5 presents an overview of the different outcomes described in the review articles. Table 5 provides an overview of the improved patient outcomes (collaboration between physicians and nurses led to better results for these outcomes), Table 6 shows an overview of the equivalent patient outcomes (collaboration between physicians and nurses led to equal results for these outcomes) and Table 7 presents an overview of the mixed patient outcomes (collaboration between physicians and nurses led to better and/or equal and/or worse results for these outcomes). Blood pressure, patient satisfaction and hospitalization are the outcomes where three or more systematic reviews concluded better results when physicians and nurses collaborated, compared to usual care. Systematic reviews often described a combination of improved and equivalent patient outcomes when the included articles showed mixed results.

Table 8 describes the collaboration between physicians and nurses in the different review articles. Collaboration was described as a 'multidisciplinary', 'inter-disciplinary' or 'inter-professional'. Other health care providers are often part of the team [20, 21, 26, 27].

Figure 2 presents the nursing roles/tasks in the collaboration with physicians in the included systematic reviews. The most frequently represented tasks are: specific nursing tasks (e.g. blood pressure control), communication/consultation tasks (e.g. communication with the multidisciplinary team), patient education tasks (e.g. lifestyle counseling) and coordination/organization/referral tasks (e.g. coordination of care, conducting a discharge planning). Two review articles did not clearly describe the tasks performed by the nurses.

\section{Discussion}

Eleven systematic reviews describing the impact of collaboration between physicians and nurses on patient outcome were included in this overview of systematic reviews. Collaboration between physicians and nurses may have a positive impact on a number of patient outcomes and on a variety of pathologies.

Almost fifty different patient outcomes were described (Table 3). In most reviews, it was concluded that nurses do have added value. Maybe we observe some publication bias here since most of the author groups included nurses [30]. We also obtained mixed results in the other reviews. Blood pressure was the only patient outcome exclusively reported as improved in three different systematic reviews [19, 21, 28]. Two of them even performed a meta-analysis [21, 28]. Patient satisfaction is an improved patient outcome as well. No less than five different systematic reviews confirmed this [19, 20, 22, 26, 27]. However, two systematic reviews reported an equivalent patient satisfaction when physicians and nurses collaborated [22, 23]. Number of hospitalization is another improved patient outcome, confirmed by four different systematic reviews $[19,20,22,26]$. However, three systematic reviews [20, 23, 26] also reported an equivalent number of hospitalizations and one [22] even reported an increase of hospitalizations when physicians and nurses collaborated. These mixed results make it difficult to make an accurate interpretation and conclusion towards the different patient outcomes.

Colorectal screening, hospital length of stay and health-related quality of life are three patient outcomes that also improved when physicians and nurses did not collaborate. However, only colorectal screening and health-related quality of life were merely categorized as negative outcomes. Allen et al. reported the length of hospital stay as a negative outcome. But the same review article also reported improvement in length of hospital stay, as well as two other review articles [20, 23]. Quality of life in general was reported as an improved outcome when physicians and nurses collaborated in two different review articles [26, 27].

The included systematic reviews often combined different interventions such as patient education [22, 29], medication adjustment [28], discharge planning protocol and shared decision making $[21,22]$ while measuring patient outcomes. Adding one or more interventions, besides collaboration between physicians and nurses, also makes it more difficult to determine which effect can be attributed to which intervention.

The evidence of collaboration between physicians and nurses on patient outcome can be applied to the primary care setting for almost all the measured patient outcomes. Only two systematic reviews included articles conducted in a hospital setting [25, 27]. Therefore, the improvement of global quality of life, and the decline of patient falls and pressure ulcers cannot be allotted to collaboration between physicians and nurses in the primary care setting.

\section{Collaboration}

The different systematic reviews used a variety of terms describing the collaboration between health care providers including inter-professional collaboration, multidisciplinary collaboration, coordination, communication, teamwork and shared care. A clear definition and subsequent 


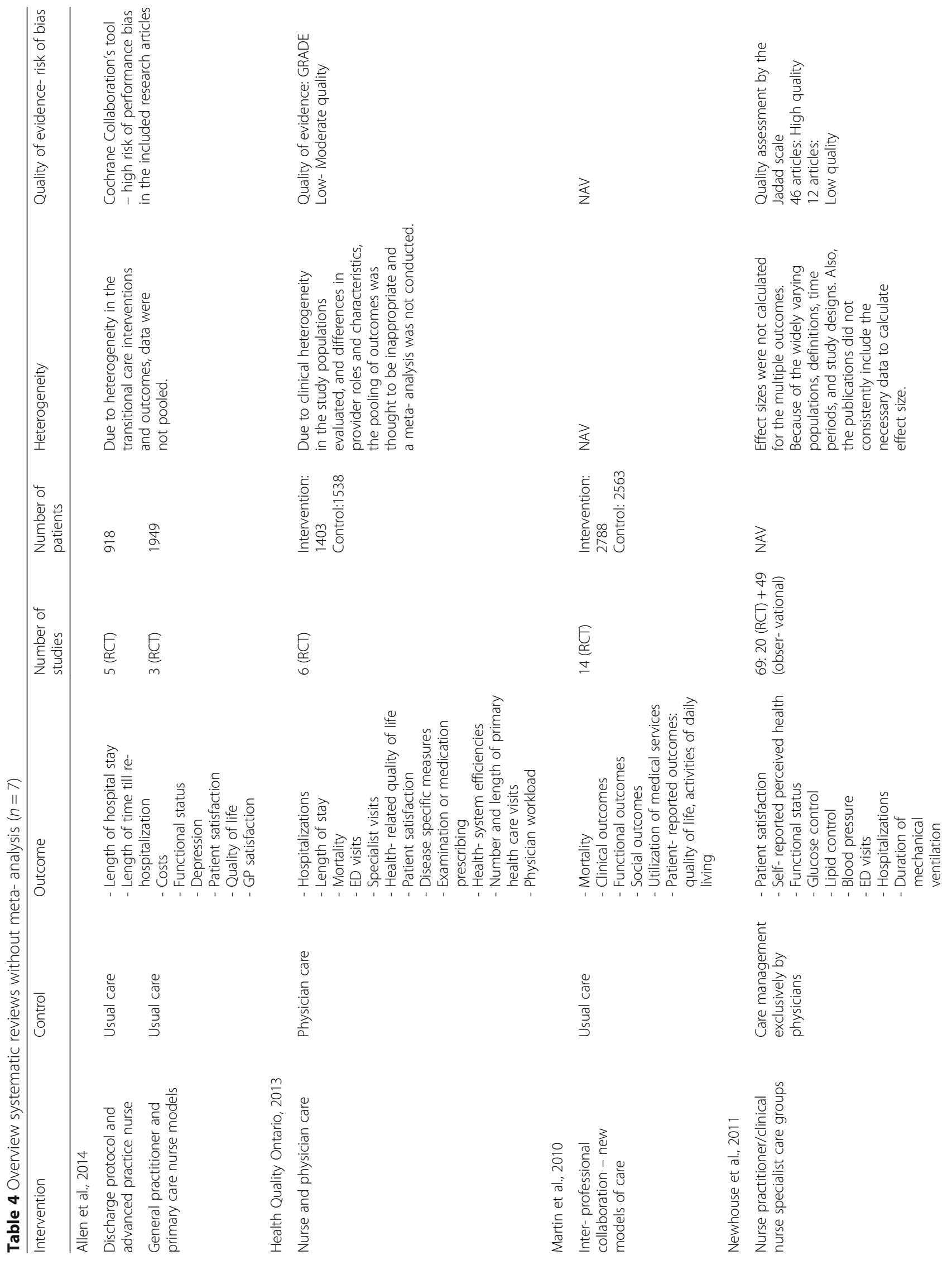




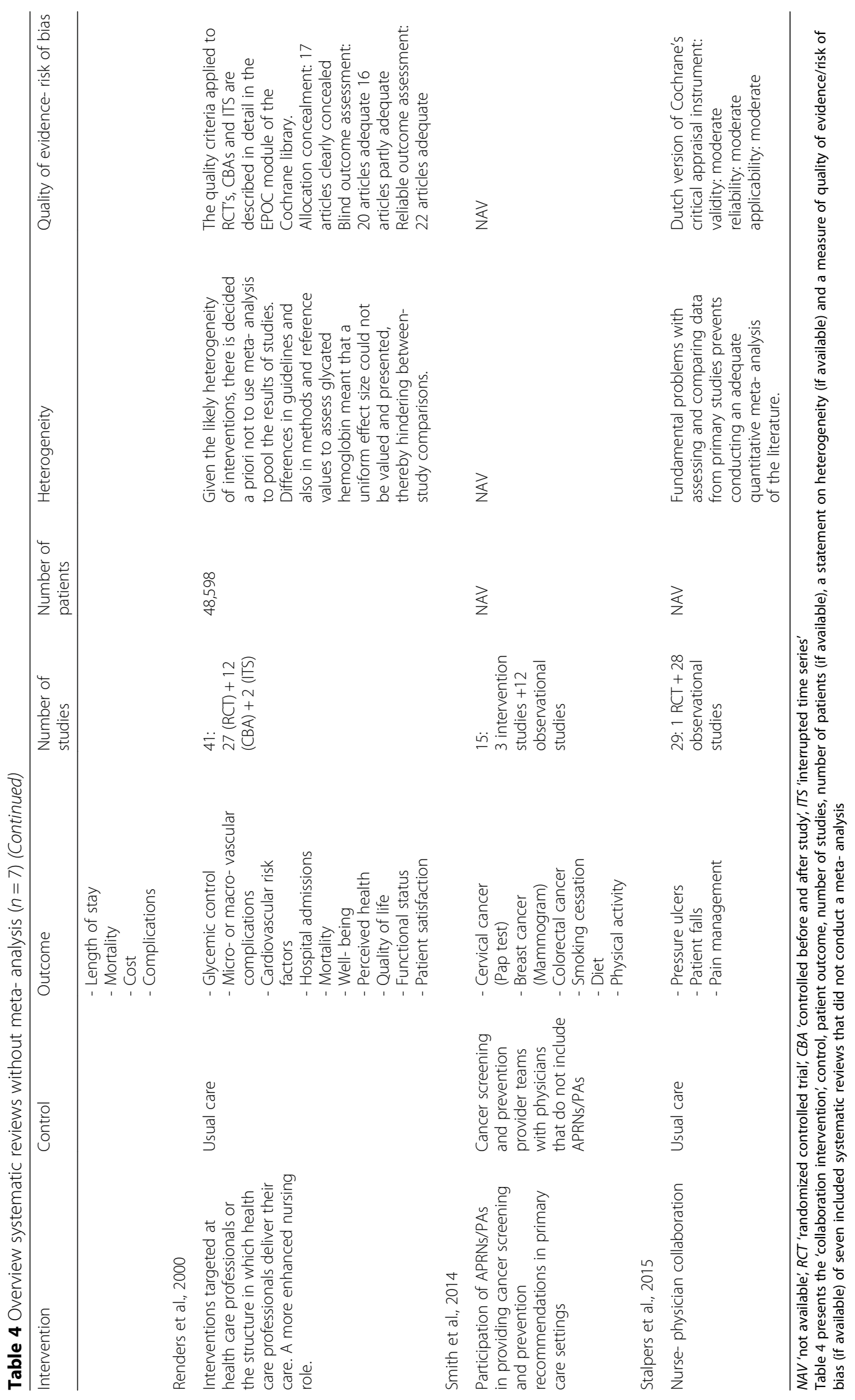


Table 5 Overview improved patient outcomes

\begin{tabular}{|c|c|}
\hline Serum lipid levels & Newhouse et al., Snaterse et al. \\
\hline Cervical and breast cancer screening & Smith et al. \\
\hline Lower cost of care & Newhouse et al., Allen et al. \\
\hline Patient falls & Stalpers et al. \\
\hline Pressure ulcers & Stalpers et al. \\
\hline Guideline adherence & Snaterse et al. \\
\hline Total cholesterol & Health Quality Ontario 2013, Snaterse et al. \\
\hline Low density lipoprotein cholesterol & Shaw et al., Snaterse et al. \\
\hline Triglyceride & Snaterse et al. \\
\hline Pharmacological treatment & Snaterse et al. \\
\hline Blood pressure & Health Quality Ontario 2013, Shaw et al., Snaterse et al. \\
\hline SCORE $^{a}$ & Snaterse et al. \\
\hline All-cause and cardiovascular readmission days & Snaterse et al. \\
\hline Reduction in $\mathrm{HbA} 1 \mathrm{c}$ levels & Heath Quality Ontario 2013, Shaw et al. \\
\hline Self-perceived health & Martin et al. \\
\hline Life satisfaction & Aubin et al., Martin et al. \\
\hline Symptom severity & Aubin et al., Health Quality Ontario 2014. \\
\hline Quality of life & Aubin et al., Health Quality Ontario 2014. \\
\hline Delay in re-hospitalization & Allen et al. \\
\hline Improved referral to community services & Allen et al. \\
\hline General practitioner satisfaction & Allen et al. \\
\hline Discharge communication to general practitioners & Allen et al. \\
\hline Informal caregiver satisfaction & Health Quality Ontario 2014. \\
\hline Increase likelihood of dying at home (end-of-life care) & Health Quality Ontario 2014. \\
\hline Decrease likelihood of dying in a nursing home (end-of-life care) & Health Quality Ontario 2014. \\
\hline Reduction of intensive care unit admission & Health Quality Ontario 2014. \\
\hline $\begin{array}{l}\text { Number of clinical examinations for blood pressure, } \mathrm{BMI}^{\mathrm{b}} \text { and } \\
\text { smoking status }\end{array}$ & Health Quality Ontario 2013. \\
\hline Number of foot examinations (diabetes) & Health Quality Ontario 2013 \\
\hline \multicolumn{2}{|l|}{ Patient outcomes also presented in Tables 6 or 7} \\
\hline Smoking cessation recommendations & Smith et al., Snaterse et al. \\
\hline Hospital length of stay & Allen et al., Martin et al., Newhouse et al. \\
\hline Diet & Snaterse et al. \\
\hline Patient satisfaction & $\begin{array}{l}\text { Aubin et al., Allen et al., Health Quality Ontario 2013, Health Quality Ontario } \\
\text { 2014., Martin et al. }\end{array}$ \\
\hline Hospitalization rates & Allen et al., Health Quality Ontario 2013, Health Quality Ontario 2014., Martin et al. \\
\hline Emergency department visits & Health Quality Ontario 2014., Martin et al. \\
\hline Glycaemic control & Renders et al. \\
\hline Mortality & Martin et al. \\
\hline Physical, emotional and social functioning & Martin et al. \\
\hline
\end{tabular}

Table 5 presents the patient outcomes that were found to be improved (by one or more systematic reviews) when physicians and nurses collaborate, compared to no collaboration

${ }^{a} S C O R E$ Systematic Coronary Risk Evaluation. It's a comprehensive cardiovascular risk algorithm designed for the primary prevention setting

${ }^{\mathrm{b}} B M I$ Body Mass index

elaboration of the nature of the collaboration was lacking in most of the reviews. This is consistent with findings in the existing literature, where there seems to be no agreement on the use of terms to describe collaboration between health professionals [31]. This also makes it difficult to know how the collaboration translates itself in daily 
Table 6 Overview equivalent patient outcomes

\begin{tabular}{ll}
\hline Patient satisfaction & Allen et al., Newhouse et al. \\
Self-reported perceived health & Newhouse et al. \\
Functional status outcomes & Allen et al., Newhouse et al. \\
Glycaemic control & Newhouse et al. \\
Blood pressure control & Newhouse et al. \\
Emergency department visits & Newhouse et al. \\
Hospitalization rates & Health Quality Ontario 2014., Martin et al., Newhouse et al. \\
Mortality & Martin et al., Newhouse et al. \\
Hospital length of stay & Health Quality Ontario 2014., Martin et al., Newhouse et al. \\
Recommendation of mammograms & Smith et al. \\
Smoking cessation recommendations & Smith et al. \\
Diet and physical therapy recommendations & Smith et al. \\
Depression & Allen et al. \\
Number of clinical examination of cholesterol & Health Quality Ontario 2013. \\
Utilisation of medical services & Martin et al. \\
Number of transfers & Martin et al. \\
Physical, emotional and social functioning & Martin et al. \\
Activities of daily living (ADL) & Martin et al. \\
\hline
\end{tabular}

Table 6 presents the patient outcomes that were found to be equal (by one or more systematic reviews) when physicians and nurses collaborate, compared to no collaboration

practice: were the studied collaborations between physicians and nurses merely focused on nurses performing dedicated tasks, based on physicians orders (a rather more instrumental collaboration)? Or were the studied collaborations focused on nurses' competences and tasks with autonomous decision-making capacity, based on structured agreements between nurses and physicians (a rather more integrated collaboration)?

A total of 173 RCTs were finally included in this overview of systematic reviews. Although RCTs are the gold standard in establishing a firm evidence base in quantitative research, complex practice settings like health service settings, often require a more diverse methodology [32]. The relationship between teamwork and patient outcomes seems to be difficult to investigate with RCTs. A Cochrane review on interventions to promote collaboration between nurses and physicians concluded that rigorous evaluations are difficult to conduct. This is because the interventions are complex and the intermediate processes are difficult to assess [33]. Researchers in

Table 7 Overview mixed patient outcomes

\begin{tabular}{lc}
\hline $\begin{array}{l}\text { Colorectal screening } \\
\text { hospitalization rates }\end{array}$ & Smith et al. \\
Hospital length of stay & Allen et al. \\
$\begin{array}{l}\text { Table } 7 \text { presents the patient outcomes that were found to be improved and/ } \\
\text { or equivalent and/or declined }\end{array}$
\end{tabular}

the United Kingdom increasingly use qualitative research methods alongside RCTs to gain a more comprehensive understanding of the impact of health service delivery [32]. Direct observation of collaborative practice in primary care settings holds promise as a method to better understand and articulate the complex phenomena of inter-professional collaboration. Despite methodological challenges, observation data may contribute in a unique way to the teamwork discourse by identifying elements of inter-professional collaboration that are not so obvious to caregivers when asked to self-report [34].

Open communication between physicians and nurses is an important element of collaboration that appeared to be appreciated [25]. More often, researchers reported that deficiencies in collaboration and communication between healthcare professionals have a negative impact on the provision of health care and patient outcomes [35-37]. In addition to open communication, trust, respect, shared leadership, recognition of unique contribution and collegiality are mentioned by researchers as enabling factors for good inter-professional relationships [38]. On the other hand, barriers to good inter-professional collaboration reported by researchers are time pressure, lack of explicit descriptions of each other's roles and tasks (and therefore unawareness of one another's roles and competencies), poor organizational support, absence of clear leadership, different standards and professional values, different aims and priorities, and 
Table 8 Collaboration between physicians and nurses

\begin{tabular}{|c|c|}
\hline Authors & Collaboration \\
\hline 1. Allen et al. & $\begin{array}{l}\text { Collaboration between a general practitioner and a primary care nurse in transitional care. } \\
\text { Collaboration between an advanced practice nurse and a physician during the discharge plan. }\end{array}$ \\
\hline 2. Aubin et al. & $\begin{array}{l}\text { Interdisciplinary team models of care for patients with cancer. } \\
\text { These interventions used organizational strategies such as staff organization and the creation of } \\
\text { teams of healthcare professionals working together to care for patients. } \\
\text { These interventions also used local consensus processes, formal integration of services, arrangement for } \\
\text { follow- up, coordination of assessment and treatment, and implementation of follow- up care plans. } \\
\text { The interdisciplinary treatment team included: medical oncology, social work, occupational therapy, } \\
\text { nursing, nutrition and dietetics and pastoral care. }\end{array}$ \\
\hline 3. Health Quality Ontario 2013. & $\begin{array}{l}\text { Nurses/nurse practitioners/registered nurses and physicians working in a partnership. Nurses who } \\
\text { worked in this collaboration could have been substituting or supplementing aspects of physician care. }\end{array}$ \\
\hline 4. Health Quality Ontario 2014. & $\begin{array}{l}\text { An end- of- life care team contained at least a medical doctor and a registered nurse. } \\
\text { Other possible team members: } \\
\text { - social worker } \\
\text { - spiritual advisor } \\
\text { - nutritionist } \\
\text { - geriatrician } \\
\text { - pharmacist } \\
\text { - dietician } \\
\text { Team services included: } \\
\text { - symptom management } \\
\text { - psychosocial care } \\
\text { - development of patient care plans } \\
\text { - end- of- life care planning } \\
\text { - coordination of care }\end{array}$ \\
\hline 5. Martin et al. & $\begin{array}{l}\text { Inter- professional collaboration in the care for elderly with (chronic) diseases. } \\
\text { Collaboration between at least (advanced practice) nurses and (primary care) physicians. Other care providers: } \\
\text { - social worker } \\
\text { - physio- occupational therapist } \\
\text { - pharmacist } \\
\text { - psychiatrist } \\
\text { - - ... }\end{array}$ \\
\hline 6. Newhouse et al. & $\begin{array}{l}\text { Advanced practice registered nurses (APRN)/ clinical nurse specialists delivered care in collaboration with } \\
\text { physicians. }\end{array}$ \\
\hline 7. Renders et al. & $\begin{array}{l}\text { The multidisciplinary team was led by a nurse educator. } \\
\text { There was a joint general practitioner- nurse review system in combination with arrangements for follow up. }\end{array}$ \\
\hline 8. Shaw et al. & Collaboration according to nurse- managed protocols in the care for adults with elevated cardiovascular risk. \\
\hline 9. Smith et al. & $\begin{array}{l}\text { APRN and Practice Assistants (PAs) provided cancer screening and prevention recommendations in } \\
\text { collaboration with physicians. }\end{array}$ \\
\hline 10. Snaterse et al. & $\begin{array}{l}\text { Multidisciplinary consultation for patients with coronary heart diseases. } \\
\text { Collaboration between nurses and general practitioners or cardiologists. } \\
\text { The following strategies were used: } \\
\text { - Risk factor management. } \\
\text { - Multidisciplinary consultation. } \\
\text { - Shared decision- making. }\end{array}$ \\
\hline 11. Stalpers et al. & Collaborative nurse- physician relationships in the care for hospitalized patients. \\
\hline
\end{tabular}

Table 8 presents an overview of the interpretation of collaboration between physicians and nurses (and other health care providers) within the eleven included systematic reviews

vertical management structures with discriminatory power structures [39-41].

\section{Nursing roles}

Although the review articles often lacked a comprehensive description of the nursing roles in collaboration with physicians, we identified seven different categories of nursing roles in the systematic reviews in our review. 'Nursing tasks' and 'drug prescription' may be more distinct instrumental roles or nursing tasks, and are probably based on physicians' orders. 'Communication/consultation' and 'coordination/organization/referral' may be rather more related to integrated nursing roles with nurses' autonomous decision-making capacity based on structured agreements between nurses and physicians. Existing literature confirms the nursing skill mix, and the shift from task delegation to team care with shared responsibilities [42, 43]. Two systematic 


\section{Overview of the nursing roles in the collaboration with physicians}

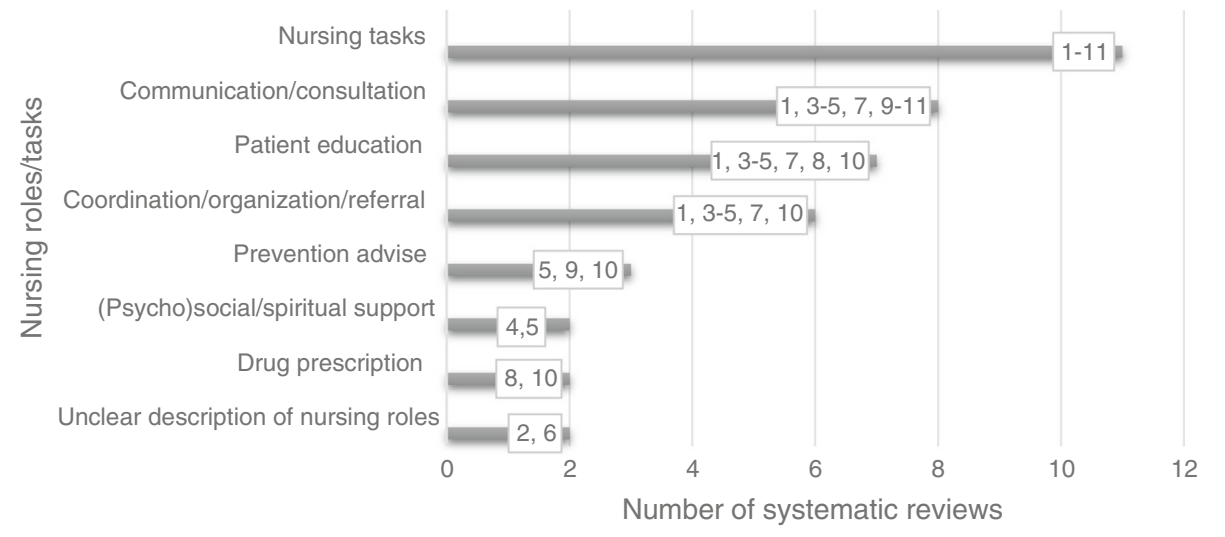

Fig. 2 Overview of the nursing roles in the collaboration with physicians. Presents an overview of the 7 different nursing roles in collaboration with physicians within the eleven included systematic reviews. 2 systematic reviews failed to give a clear description of the nursing roles. The numbers within the graph represent the eleven included systematic reviews

reviews failed to describe the nature of the nursing roles and their responsibilities [23, 27]. Furthermore, nursing titles differed across the included systematic review articles and ranged from 'advanced practice (registered) nurses', 'nurse practitioners', 'registered nurses,' 'primary care nurses', 'clinical nurses specialists' and 'practice assistants'. The literature confirms the increasing diversity of the primary care workforce. A wider range of health professionals is included, such as those mentioned above [43]. The difference in professional titles might be attributed to a difference in education, which points out the importance of (postgraduate) education of nurses, especially in collaboration with physicians [29]. Expanding the role of primary care nurses is possible with appropriate training and on-going support from primary care physicians [44]. Improving care quality requires investing in a distinct primary care workforce that has followed a defined program of post-graduate training in primary care [2].

\section{Strengths and limitations}

A comprehensive research was performed and the methodological quality of the included review articles was carefully assessed. Overall, the quality of available systematic reviews on this research topic appeared to be limited. 15 potentially useful systematic reviews were excluded based upon an inadequate methodological quality. The included systematic review articles were heterogeneous in terms of patient populations, setting, type of nurse and geographic region. Limited descriptions of the collaboration, and the different nursing and physician roles in the included systematic reviews are limitations of this overview of systematic reviews. The included systematic reviews often lacked a detailed description of the evidence of the different primary studies, therefore it is difficult to make conclusions about the strength of the evidence of the results. For future systematic reviews concerning this research topic we suggest to define more precisely the nature of the collaboration between the two professions and to provide a clear description of the concept of inter-professional collaboration.

Primary research articles concerning this research topic within the primary care setting are often limited to one pathology or diagnosis. However, the patient population in primary care presents itself with a wide range of pathologies. This overview of systematic reviews provides a more comprehensive view on the impact of collaboration between physicians and nurses in primary care on a wide variety of patient outcomes, for a wide range of patients.

Future research is necessary to define 'integrated interprofessional collaboration' in primary care more clearly, and to explore the impact of this collaboration on relevant patient and health care provider outcomes. These include hospital (re)admissions of patients with chronic conditions, patient satisfaction and primary health care provider satisfaction. We suggest using complementary methods to find a more robust evidence base for the collaboration of nurses and general practitioners in primary care.

\section{Implications for practice}

This overview of systematic reviews provides a firm evidence base to engage practice nurses in general practices. Moreover, current and future challenges in primary care require a more integrated inter-professional collaboration instead of a task shift between general practitioners and nurses. Therefore, we recommend that collaboration between health care providers should be well described 
and discussed concerning roles, tasks and responsibilities of individual caretakers. A clear description is important in order to address the needs of the patient populations, and in order to address the individual patient needs.

\section{Conclusion}

This overview of systematic reviews shows that collaboration between physicians and nurses may have a positive impact on a number of patient outcomes and on a variety of pathologies. To address future challenges of primary care, there is a need for more integrated inter-professional collaboration and sufficiently educated nurses.

\section{Additional files}

Additional file 1: Search terms. Presents the search terms used within the different databases. (DOCX $12 \mathrm{~kb}$ )

Additional file 2: Reference list of primary research articles. Presents the references of all the primary research articles included in the systematic reviews. (DOCX $64 \mathrm{~kb}$ )

\section{Abbreviations}

(HR)QOL: Health related quality of life; ADL: Activities of daily living; APRN: Advanced practice registered nurse; $B C l$ : Bootstrap confidence interval; BMl: Body mass index; BP: Blood pressure; CAD: Coronary artery disease; CBA: Controlled before and after study; CHF: Chronic heart failure; $\mathrm{Cl}$ : Confidence interval; CNS: Clinical nurse specialist; COPD: Chronic obstructive pulmonary disease; GP: General practitioner; ICU: Intensive care unit; ITS: Interrupted time series; LDL: Low density lipoprotein; NA: Not applicable; NAV: Not available; NCC: Nurse coordinated care; NICU: Neonatal intensive care unit; NP: Nurse practitioner; PA: Physician assistant;

RCT: Randomized controlled trial; SCORE: Systematic coronary risk evaluation

\section{Acknowledgements}

We thank native speaker mrs Jude Murison for providing feedback on the manuscript.

\section{Funding}

The first author, Evi Matthys, received a scholarship from the home care organization 'Wit-Gele Kruis van Antwerpen VZW', to perform a part time PhD. Prof. Dr. Peter Van Bogaert and Prof. Dr. Roy Remmen are full-time academics. All authors declare no conflict of interest. 'Wit-Gele Kruis van Antwerpen VZW' has no role in the design of the study and collection, analysis, and interpretation of data in writing the manuscript.

\section{Availability of data and materials}

All data generated or analyzed during this study are included in this published article and its Additional files.

\section{Authors' contributions}

EM searched the databases, reviewed titles, abstracts and full texts, and drafted the manuscript. RR reviewed titles, abstracts and full texts, and drafted the manuscript. PVB reviewed titles, abstracts and full texts, and drafted the manuscript. All authors read and approved the final manuscript.

\section{Ethics approval and consent to participate}

Not applicable.

\section{Consent for publication}

Not applicable.

\section{Competing interests}

The authors declare that they have no competing interests.

\section{Publisher's Note}

Springer Nature remains neutral with regard to jurisdictional claims in published maps and institutional affiliations.

Received: 10 April 2017 Accepted: 12 December 2017

Published online: 22 December 2017

\section{References}

1. World Health Organization. Global strategy and action plan on ageing and health (2016-2020). 2016. http://www.who.int/ageing/global-strategy/en/. Accessed 20 May 2017.

2. OECD. Health at a Glance: Europe 2016. State of Health in the EU Cycle. 4th edition. OECD publishing; 2016. p. 204.

3. Ogden J, et al. I want more time with my doctor: a quantitative study of time and the consultation. Fam Pract. 2004:21(5):479-83.

4. Kacenelenbogen N, Offermans AM, Roland M. Burnout of general practitioners in Belgium: societal consequences and paths to solutions. Rev Med Brux. 2011;32(4):413-23.

5. Goetz K, et al. The influence of workload and health behavior on job satisfaction of general practitioners. Fam Med. 2013;45(2):95-101.

6. Gerkens SM, Belgium S. Health System Review. Health Systems in Transition. 2010;12(5):1-266.

7. Berwick DM, Nolan TW, Whittington J. The triple aim: care, health, and cost. Health Aff (Millwood). 2008;27(3):759-69.

8. Kringos DSB, Hutchinson A WGW, Saltman RB. Building Primary Care in a Changing Europe: Case Studies. European Observatory on Health Systems and Policies. 2015;38:172

9. Hildebrandt $\mathrm{H}$, et al. Pursuing the triple aim: evaluation of the integrated care system Gesundes Kinzigtal: population health, patient experience and cost-effectiveness. Bundesgesundheitsblatt Gesundheitsforschung Gesundheitsschutz. 2015;58(4-5):383-92.

10. Sikka R, Morath JM, Leape L. The quadruple aim: care, health, cost and meaning in work. BMJ Qual Saf. 2015:24(10):608-10.

11. van Uden CJ, Crebolder HF. Does setting up out of hours primary care cooperatives outside a hospital reduce demand for emergency care? Emerg Med J. 2004;21(6):722-3.

12. Laurant $M$, et al. Substitution of doctors by nurses in primary care. Cochrane Database Syst Rev. 2005. doi:10.1002/14651858.CD001271.pub2.

13. van Loenen $T$, et al. Organizational aspects of primary care related to avoidable hospitalization: a systematic review. Fam Pract. 2014;31(5):502-16.

14. Longman JM, et al. Admissions for chronic ambulatory care sensitive conditions - a useful measure of potentially preventable admission? BMC Health Serv Res. 2015;15:472.

15. Shea BJ, et al. Development of AMSTAR: a measurement tool to assess the methodological quality of systematic reviews. BMC Med Res Methodol. 2007:7:10

16. Shea BJ, et al. AMSTAR is a reliable and valid measurement tool to assess the methodological quality of systematic reviews. J Clin Epidemiol. 2009; 62(10):1013-20.

17. Pollock M, Fernandes RM, Hartling L. Evaluation of AMSTAR to assess the methodological quality of systematic reviews in overviews of reviews of healthcare interventions. BMC Med Res Methodol. 2017:17(1):48.

18. Shea BJ, et al. External validation of a measurement tool to assess systematic reviews (AMSTAR). PLoS One. 2007;2(12):e1350.

19. Specialized nursing practice for chronic disease management in the primary care setting: an evidence-based analysis. Ont Health Technol Assess Ser. 2013;13(10):1-66.

20. Martin, J.S., et al., Interprofessional collaboration among nurses and physicians: Making a difference in patient outcome. Swiss Med. Wkly, 2010. 140(SEPTEMBER).

21. Snaterse M, et al. Effective components of nurse-coordinated care to prevent recurrent coronary events: a systematic review and meta-analysis. Heart. 2016;102(1):50-6.

22. Allen J, et al. Quality care outcomes following transitional care interventions for older people from hospital to home: a systematic review. BMC Health Serv Res. 2014:14:346.

23. Newhouse, R.P., et al., Advanced practice nurse outcomes 1990-2008: a systematic review. Nurs Econ, 2011. 29(5): p. 230-250; quiz 251.

24. Smith AA, Kepka D, Yabroff KR. Advanced practice registered nurses, physician assistants and cancer prevention and screening: a systematic review. BMC Health Serv Res. 2014;14:68. 
25. Stalpers D, et al. Associations between characteristics of the nurse work environment and five nurse-sensitive patient outcomes in hospitals: a systematic review of literature. Int J Nurs Stud. 2015;52(4):817-35.

26. Team-Based Models for End-of-Life Care: An Evidence-Based Analysis. Ont Health Technol Assess Ser. 2014;14(20):1-49.

27. Aubin $\mathrm{M}$, et al. Interventions to improve continuity of care in the follow-up of patients with cancer. Cochrane Database Syst Rev. 2012. doi:10.1002/ 14651858.CD007672.pub2.

28. Shaw RJ, et al. Effects of nurse-managed protocols in the outpatient management of adults with chronic conditions: a systematic review and meta-analysis. Ann Intern Med. 2014;161(2):113-21.

29. Renders Carry $M$, et al. Interventions to improve the management of diabetes mellitus in primary care, outpatient and community settings. Cochrane Database Syst Rev. 2000. doi:10.1002/14651858.CD001481.

30. Dwan $\mathrm{K}$, et al. Systematic review of the empirical evidence of study publication bias and outcome reporting bias - an updated review. PLoS One. 2013;8(7):e66844.

31. Mahler C, et al. Terminology for interprofessional collaboration: definition and current practice. GMS Z Med Ausbild. 2014;31(4):Doc40.

32. O'Cathain A, Murphy E, Nicholl J. Why, and how, mixed methods research is undertaken in health services research in England: a mixed methods study. BMC Health Serv Res. 2007:7:85.

33. Zwarenstein $\mathrm{M}, \mathrm{Bryant} \mathrm{W}$. Interventions to promote collaboration between nurses and doctors. Cochrane Database Syst Rev. 2000;2:CD000072.

34. Morgan S, Pullon S, McKinlay E. Observation of interprofessional collaborative practice in primary care teams: an integrative literature review. Int J Nurs Stud. 2015;52(7):1217-30.

35. Rosenstein, A.H. and M. O'Daniel, Disruptive behavior and clinical outcomes: perceptions of nurses and physicians. Am J Nurs, 2005. 105(1): p. 54-64; quiz 64-5.

36. Manojlovich M, DeCicco B. Healthy work environments, nurse-physician communication, and patients' outcomes. Am J Crit Care. 2007;16(6):536-43.

37. Zwarenstein $\mathrm{M}$, et al. Structuring communication relationships for Interprofessional teamwork (SCRIPT): a cluster randomized controlled trial. Trials. 2007:8:23.

38. Schmalenberg C, et al. Excellence through evidence: securing collegial/ collaborative nurse-physician relationships, part 1. J Nurs Adm. 2005;35(10): 450-8.

39. Xyrichis $\mathrm{A}$, Lowton $\mathrm{K}$. What fosters or prevents interprofessional teamworking in primary and community care? A literature review. Int I Nurs Stud. 2008;45(1): 140-53.

40. Supper I, et al. Interprofessional collaboration in primary health care: a review of facilitators and barriers perceived by involved actors. J Public Health (Oxf). 2015:37(4):716-27.

41. Davies C. Getting health professionals to work together. BMJ. 2000; 320(7241):1021-2

42. Walker L, Clendon J, Nelson K. Nursing roles and responsibilities in general practice: three case studies. J Prim Health Care. 2015;7(3):236-43.

43. Freund T, et al. Skill mix, roles and remuneration in the primary care workforce: who are the healthcare professionals in the primary care teams across the world? Int J Nurs Stud. 2015;52(3):727-43.

44. Maier, C.E.A., Nurses in Advanced Roles in Primary Care: Policy Levers for Implementation OECD Health Working Papers. Paris: OECD Publishing.

45. Steinman MA, et al. Improving antibiotic selection: a systematic review and quantitative analysis of quality improvement strategies. Med Care. 2006; 44(7):617-28.

46. Walsh JM, et al. Quality improvement strategies for hypertension management: a systematic review. Med Care. 2006;44(7):646-57.

47. Shojania KG, et al. The effects of on-screen, point of care computer reminders on processes and outcomes of care. Cochrane Database Syst Rev. 2009:3:Cd001096.

\section{Submit your next manuscript to BioMed Central and we will help you at every step:}

- We accept pre-submission inquiries

- Our selector tool helps you to find the most relevant journal

- We provide round the clock customer support

- Convenient online submission

- Thorough peer review

- Inclusion in PubMed and all major indexing services

- Maximum visibility for your research

Submit your manuscript at www.biomedcentral.com/submit
C Biomed Central 